\title{
"Os resultados desta pesquisa (qualitativa) não podem ser generalizados": pondo os pingos nos is de tal ressalva
}

\author{
"The results of this (qualitative) research cannot be generalized": dotting the i's on this \\ caveat
}

Pedro Lincoln C. L. de Mattos ${ }^{1}$

\begin{abstract}
Resumo
Em artigos, dissertações e teses em administração que desenvolvem estudos de caso e análises segundo a tradição "pesquisa qualitativa" ocorre os autores advertirem o leitor que suas conclusões são restritas e que não podem ser generalizadas, autoridade que Ihes seria, ao contrário, conferida por métodos estatísticos de análise. Entende-se por "generalização" a inferência de qualidades de casos ou unidades singulares de análise para outros ou conjuntos deles que, de fato, não foram objeto de observação e análise. O objetivo deste ensaio é esclarecer criticamente o sentido da ressalva-título, supondo-se aí implícita uma ampla questão metodológica. Definida a discussão (Introdução), examinamse alguns de seus pressupostos, sobretudo a força paradigmática do positivismo. Na sequência, visita-se perspectiva de pesquisa bem diversa, a de Max Weber, a fim de experimentar salutar deslocamento epistêmico em relação à prática metodológica anterior. Volta-se à questão da generalização e examinam-se certas variações mais elaboradas dela, segundo a tradição "qualitativa", que acabam por confundir o processo lógico em questão. Pondo, finalmente, "os pingos nos is" da ressalva, conclui-se pelo caráter puramente valorativo desta e toma-se posição sobre generalização indutiva e pesquisa qualitativa, centrais ao contexto da discussão.
\end{abstract}

Palavras-chave: Generalização. Pesquisa qualitativa em administração. Análise pós-positivista.

\begin{abstract}
In articles, dissertations and theses in administration that involving case studies and analyses based on the "qualitative research" tradition, authors warn readers that their conclusions are restricted and cannot be generalized. However, on the contrary, they would be able to claim this authority by using some statistical analysis methods. The term "generalization" is understood as the conferring of qualities of cases or singular units of analysis to others or combinations of them, when these latter were not infact the object of observation and analysis. The aim of this text is to critically clarify the caveat-title in which a wide methodological issue remains implicit. After posing the question (Introduction), some assumptions of it are examined, particularly the paradigmatic force of positivism. A quite different perspective of research by Max Weber is visited in order to experience a healthy epistemic shift in relation to the previous methodological practice. The article then returns to the issue of generalization and critically examines some more elaborate variations of it. Finally, putting the dots on the is, the article concludes by suggesting the purely valuable
\end{abstract}

Artigo submetido em 22 de julho de 2010 e aceito para publicação em 26 de maio de 2011.

${ }^{1}$ Ph.D. pela The London School of Economics and Political Sciences (LSE); Professor Titular da Universidade Federal de Pernambuco. Endereço: Av. Bernardo V. de Melo, 1264, ap. 1802, Piedade, Jaboatão, CEP 54400-000, PE, Brasil. E-mail: plincoln@hotlink.com.br 
character of the caveat-title and takes a stance on bout both inductive generalization and qualitative research, two contextual, central points of this essay.

Keywords: Generalization. Qualitative research in administration. Post-positivist analysis.

\section{Introdução}

Ocorre em artigos, dissertações e teses em administração que desenvolvem estudos de caso e análises segundo a tradição "pesquisa qualitativa" os autores, ao apresentarem as limitações do trabalho, advertirem o leitor que suas conclusões são restritas e que - quase "infelizmente" - não podem ser generalizadas, autoridade que lhes seria, ao contrário, conferida por métodos estatísticos de análise. Apesar de toda a competência do tratamento metodológico, as conclusões "não podem ir além". Repetidas, em diferentes circunstâncias, como bordão, essas explicações e advertências soam como "escusas" - o autor como a reconhecer tratar-se o caso de uma espécie de estudo de "segunda linha", perfeito no seu âmbito, mas trazendo certa deficiência congênita. A questão que se pode identificar através desse fato, muitas vezes despercebido, não é trivial, e pode revelar muita coisa sobre método de pesquisa. Trata-se da afirmação implícita da hegemonia e superioridade de um processo lógico em ciência, a generalização indutiva - que aqui se afirmará não ser mais que um consenso residual em certos meios científicos.

Entende-se por generalização indutiva, ou simplesmente, "generalização", termo com mais de três séculos de uso especializado ${ }^{2}$, a inferência de qualidades de casos singulares, ou unidades de análise circunscritas, para outros casos, unidades ou conjuntos deles, que, de fato, não foram objeto de observação e análise, mesmo que sua ocorrência seja probabilisticamente restrita. Generalização, como atributo de uma proposição de pesquisa, tem o mesmo sentido que muitos autores chamam de "validade externa" (GRAY et al., 2007, p. 270; BABBIE, 1979, p. 280; MERRIAM, 1998, p. 207-212). Assim se expressa Richardson (1999, p. 87): "A validade externa refere-se à possibilidade de generalizar os resultados a outros grupos semelhantes".

O processo lógico aí envolvido é a indução, ou "inferência ampliativa” (AUDI, 1999, p. 425), onde uma conclusão, ainda que sob condições probabilísticas, infere além das premissas de observação, inclusive privilegiando, por teste, uma ou mais destas (verificação). Sendo, de fato, uma forma de pensar e argumentar muito presente no dia a dia e no senso comum, a ciência empírica lhe deu nova dimensão. Durozoi e Roussel (1996, p. 254) definem a indução como "Inferência conjectural que passa de uma regularidade observada à afirmação de sua constância". David Hume (1972 [1748]) diz ser a indução natural ao pensar humano. Para justificar metafisicamente a indução na ciência, Immanuel Kant (1974 [1787]) defendeu como necessários os juízos sintéticos a priori, ou seja, condições subjetivas transcendentais à experiência, inclusive às leis e hipóteses científicas (PASCAL, 2001, p. 43-44). A fundamentação desse método veio da filosofia, formando uma longa tradição (HESSEN, 1999, p. 14-15; WATKINS, 1984), desde os empiristas ingleses - Hume foi voz dissonante - até o positivismo lógico, forte na primeira metade do Século XX (CARNAP, 1971). Ao desfecho dessa história, que tem a ver com o nosso tema, se voltará na última seção do texto.

O ensaio pretende ser um diálogo com aquele leitor que já se inquietou ao ler a frase-título, mas, sobretudo, com o que já a escreveu, ele mesmo, em algum trabalho. O objetivo é esclarecer tal frase ou ressalva-título, refletindo criticamente e perguntando que sentido isso faz. O leitor é convidado: a examinar alguns pressupostos dela (seção seguinte); depois, a visitar perspectiva de pesquisa completamente diversa, lendo alguns trechos metodológicos de Max Weber, a fim de experimentar um salutar deslocamento epistêmico em relação à prática metodológica anterior; em seguida, a voltar à questão da generalização e examinar certas variações mais elaboradas dela, segundo a tradição de pesquisa acadêmica dita "qualitativa", que acabam por

${ }^{2}$ O Online Etymological Dictionary (http://www.etymonline.com/index.php?term=generalization) registra em 1794 o primeiro uso do termo como "inferência geral", justamente a época que se seguiu aos debates dos filósofos empiristas sobre a indução. 
esquecer o processo lógico indutivo, que subjaz à generalização, a distinção já clássica entre significação (produção de signos) e referência, e até a confundir a generalização com a natureza universal ("dessingularizada") dos simples conceitos. Na última seção - sem propor substitutivos para a ressalva-título, afinal inconsistente - conclui-se pelo caráter puramente valorativo desta e, em um excurso final, toma-se posição sobre (contra) a hegemonia da generalização indutiva na lógica das ciências e sobre a difícil posição da pesquisa qualitativa, já que estes dois casos são centrais ao contexto da presente discussão.

\section{"Resultados de pesquisa deveriam ser generalizáveis"}

A ressalva objeto desse artigo ("Os resultados desta pesquisa [qualitativa] não podem ser generalizados") inclui três significados: que os resultados de pesquisa deveriam ser generalizáveis; que a pesquisa qualitativa é um caso diferenciado; que a condição da generalização é, no caso, frustrada. Posto que este último significado fica por conta de quem faz a ressalva - e é justamente o ponto problemático - , esta seção, com subseções, reflete sobre o primeiro desses significados. O segundo significado é desenvolvido na seção "A generalização transfigurada" e suas subseções - considerando-se, depois dela, nossa ressalva-título suficientemente reconhecida.

\section{O paradigma da generalização}

Vendo-se a força da afirmação paradigmática sobre a generalização, dá-se toda razão ao pesquisador iniciante ou hesitante que se previne com a ressalva "meus resultados não podem, etc." Exemplarmente, diz Earl Babbie (1979) em seu conhecido The Practice of Social Research:

A ciência visa à compreensão geral mais que a explanação de eventos individuais. O cientista está, tipicamente, menos interessado em entender por que certa bola cai ao chão quando é solta de uma altura do que em entender por que todas as bolas como essa tendem a fazer o mesmo. [...] Essa característica da ciência está relacionada com seu determinismo probabilístico. É concebível que se possa explicar completamente as razões que jazem sob determinado evento - por que certo homem votou no candidato X. Podemos, supostamente, conceber cada fator individual que entrou na decisão de votar. Bem-sucedidos nisso, presumivelmente seríamos capazes de predizer o comportamento eleitoral de pessoas idênticas, com perfeita exatidão. No longo prazo, contudo, tal capacidade não daria muita informação útil sobre o comportamento eleitoral em geral. [...] É nesse sentido que o cientista e o historiador diferem em suas abordagens sobre o mesmo assunto tratado. (BABBIE, 1979, p. 49-50)

O texto acima mostra com clareza, não só o movimento lógico da generalização (do singular para o geral), mas três pontos cruciais para entendermos o nosso problema: a) o paralelo - ou mais que isso - com as ciências naturais; b) a intenção preditiva probabilística; c) o objetivo prático, quase técnico, que motiva essa forma de ciência social ("informação útil"). A estes, deve-se acrescentar mais um: o engenhoso recurso "universo $\rightarrow$ amostra $\rightarrow$ universo", que trabalha com o conceito de representatividade (que, no caso, gera a relação constituinte da amostra para com o seu universo). 
A pesquisa social que aceitar esse paradigma ${ }^{3}$ precisa realmente desculpar-se quando dele se afastar. São inquestionáveis a legitimidade do método das ciências naturais e a daqueles usos na pesquisa social e tecnológica que, com propriedade, nele se apoiam. No entanto, a pesquisa que trabalha fora dele não tem por que fazer ressalvas, e deve ler com tolerância (!) julgamentos que ele, com suas leis, lança contra ela no tribunal armado na academia - como o faz o mesmo autor: "A grande fraqueza da pesquisa de campo é em relação às normas científicas sobre a possibilidade de generalização." (BABBIE, 1979, p. 228). As seções seguintes desdobrarão esse argumento.

\section{O ideal histórico da generalização}

Para entender a força e o apelo da ideia de generalização, é preciso lembrar o peso cultural de milênios que traz consigo. Todo tratado de ciência (ou de filosofia da ciência) começa dizendo que foi a necessidade de fazer previsões e resolver problemas práticos a partir de experiência anterior que impulsionou o conhecimento metódico, aliás, apenas prolongando a qualidade do conhecimento de senso comum vigente na sociedade onde surgiu. Isso se consolidou, ao longo de séculos, em torno da ideia de "lei natural". Descobrir e formular melhor as tendências regulares sobre as quais se montam previsões singulares foi e tem sido o objetivo da pesquisa nas ciências naturais e suas aplicações, sobretudo as engenharias e a medicina. Desvendados os segredos da natureza, a humanidade encontraria sua emancipação dos males sociais e individuais - pensava o homem do renascimento iluminista do Séc. XVII.

O método para tal veio a fixar-se nos séculos XVIII e XIX: o empirismo experimental, ou, simplesmente "empirismo" (HESSEN, 1999, p. 54-59). Chalmers (1999) o expressa bem: "O filósofo Francis Bacon e muitos de seus contemporâneos sintetizaram a atitude científica da época ao insistirem que, se quisermos compreender a natureza, devemos consultar a natureza, e não os escritos de Aristóteles.” (p. 23) O método consistia em fazer observações sob teste, em número e rigor tais que permitissem a generalização, a qual poderia ser aplicada a situações práticas ou voltar, na condição de hipótese, a nova observação verificadora, para confirmação. Daí surgia, seguramente, a certeza, depois sistematizada em "leis", e os cuidados na formulação destas atingiam retroativamente às hipóteses sob teste.

O ideal da generalização, portal do conhecimento verdadeiro, incorporou-se às ciências empíricas ditas "naturais" com suas três condições: a) o rigor da observação (coleta de dados e testes), representando a prevenção do pesquisador contra a ilusão de seus sentidos e as inclinações pessoais enganosas; b) a lógica indutiva, que produzia o salto generalizador, e, c) uma linguagem clara, precisa e universal para expressar o conhecimento. A partir de Newton e outros cientistas do século XVIII, tal linguagem seria preferentemente a matemática, apesar de tratar-se de uma linguagem formal. Esse era o conhecimento objetivo. Nada mais a alterar, pelos séculos seguintes.

Comte (1983 [1830-1842]) entendia o social como um "terceiro" e independente nível de realidade e por isso os fenômenos sociais podiam ser estudados ao lado dos físicos e biológicos. A ideia de fenômeno, um objeto de observação individualizada e sistemática chegou até nós. Com o prestígio social ímpar das ciências naturais, o método da sociologia positiva foi consolidado por Émile Durkheim (1858-1917), que o levou adiante, entre outras coisas, por entender que os fenômenos sociais devem ser tratados com absoluta objetividade, por suas características externas: "são coisas, pois não existem na natureza senão coisas"

3 "Paradigma" é entendido aqui como um consenso prático sobre a maneira - frequentemente um modelo - de trabalhar em ciência, que tente a manter em relativa unidade uma comunidade científica, mesmo na ausência de teoria ou no dissenso em relação a ela. Esta acepção do termo é a que Thomas Kuhn - que a lançou para o contexto da ciência - reconheceu primeiro em uma longa entrevista autobiográfica em outubro de 1995, depois de todos os debates havidos sobre o assunto, inclusive o bombástico levantado inicialmente por Margareth Masterman, em um seminário no Bradford College, Londres, em 1965. Cf. KUHN, Thomas. O Caminho desde A Estrutura. São Paulo: UNESP, 2003. p. 360-361. Note-se a diferença entre esta concepção de paradigma e a que vige em boa parte dos autores de Teoria Organizacional (MORGAN, 2007, p. 15). 
(DURKHEIM, 1990 [1895], p.17, grifo nosso), e lhes é essencial a externalidade e coerção sobre os indivíduos. Esse reforço à ideia comteana de fenômeno-objeto natural mantinha intrínseca ao positivismo a indução e a generalização pós-teste empírico (DURKHEIM, 1990 [1895], p. 123-124).

A nova ciência veio a ter inúmeros desdobramentos, de maior ou menor reconhecimento, aí se localizando a própria administração. As três características originárias do método científico, indicadas pouco acima, foram "geneticamente" herdadas, e sua ampla aceitação nas comunidades científicas veio a consolidar o paradigma de conhecimento moderno (SANTOS, 2000, p. 60-68).

Contudo, na primeira metade do Século XX, a universalidade do método sonhado como definitivo entrou em crise. O projeto de uma linguagem exata, mas não formal (como a matemática), para a ciência, capaz de representar a realidade tal como ela é, desapareceu a partir da queda do positivismo lógico, já simbolizado pela substituição, pelo próprio autor, Ludwig Von Wittgenstein, do Tractatus Logico-Filosoficus (1968 [1921]) pelo seu Investigações Filosóficas (1979 [1953]). A insustentabilidade lógica da indução, desde Hume sob suspeita, veio claramente à luz com Popper e com ela ruiu a certeza absoluta da verificação, obrigando a dar-se um novo sentido ao teste empírico. Os estudos de história da ciência deixaram claro que a explicação sócio-histórica dos fatos da ciência não dava espaços para sustentar-se um "contexto da justificação" (conceito do empirismo lógico) onde teriam lugar virtudes racionais e únicas do método científico em si, ele próprio um grande "breakthrough" da civilização ocidental. Ao final deste ensaio (5.2), se voltará mais detalhadamente a essa questão.

Hoje, quando o próprio conceito de "lei científica" não desperta mais entusiasmo (GIERE, 1999), o ideal da generalização já é visto a distância, e a própria prática metodológica da generalização (no sentido estrito aqui entendido), embora legítima, tem uso restrito - circunstância que é preciso, em ocasiões como esta, voltar a lembrar. Mesmo assim, como gentis mesuras (lembranças da Belle Époque?), a generalização ainda desperta, nas ciências sociais, reverências acadêmicas irresistíveis.

\section{Tornamo-nos todos positivistas?}

A seção anterior tentou mostrar que o contexto metodológico da generalização chegou à sociologia, sobretudo através do positivismo. Contudo, a evolução do positivismo do Século XIX ao longo do Século XX foi extremamente diversificada. É importante salientar que, embora originado na França, o positivismo alimentou a pesquisa social empírica nos Estados Unidos, consolidando-se entre as décadas de 40 e 60 do século passado, e de lá voltando a expandir-se fora daquele país com o sucesso do sistema acadêmico americano que lidera hoje, mundialmente, um circuito de pesquisa social que inclui setores da Inglaterra, Canadá, Austrália e Europa continental. Para a tradição dos estudos organizacionais, o positivismo chegou a ser sugerido como um aglutinador de tendências e proteção contra a fragmentação de abordagens (PFEFFER, 1995).

A forte marca desse sistema acadêmico entre nós no Brasil foi demonstrada por Vergara (2005, p. 35-49, texto que reúne quatro pesquisas anteriormente publicadas). A predominância da orientação metodológica positivista - ou funcionalista, cujas bases sociológicas estão no positivismo - na produção acadêmica no Brasil tem sido interpretada como um dos fatores que ocasionaram o desenvolvimento, entre nós, dos estudos críticos (DAVEL e ALCADIPANI, 2005, p. 67). Tal predominância aparece clara em outros estudos específicos de levantamento da produção nacional, como em Recursos Humanos (TONELLI, CALDAS, LACOMBE et al., 2003); em Marketing (SAMPAIO e PERIN, 2006) e em Contabilidade (NASCIMENTO, MARTINS e JUNQUEIRA, 2010; MENDONÇA NETO, RICCIO e SAKATO, 2009). O último desses estudos faz referência à pesquisa mostrando igual tendência no exterior. Aliás, em perspectiva ampla e internacional, dizem Alvesson e Kärreman (2007, p. 1266): "A maior parte da pesquisa social quantitativa e qualitativa, como a Grounded Theory, parece estar baseada em pressupostos neopositivistas". 
O que é "geneticamente" próprio a essa sociologia original, do ponto de vista das práticas metodológicas? Ao fixar-se a atenção apenas nesse aspecto, deve-se notar que o positivismo teve uma forte dimensão política em Comte e Durkheim, citados acima, e que foram seus fundamentos epistemológicos que entraram em crise no Século XX, permanecendo os hábitos de pesquisa em processo de ajuste e "miscigenação". Boa parte da "pesquisa qualitativa" está presa a dessa história. Interessa, no entanto, aqui, rever os elementos mais resistentes e os que comandam tal processo de ajustes múltiplos, parcialmente lembrados adiante, na seção "A generalização transfigurada" e suas subseções.

Referindo-se ao trabalho de Bryant (Positivism in Social Theory and Research, 1985), diz Túlio Barreto:

Bryant prefere usar o termo "positivismo instrumental" para designar esse mesmo tipo de pesquisa social empírica, bastante difundida nos Estados Unidos, que ele chega a considerar, até mesmo, a pesquisa social norte-americana característica. Ela seria instrumental na medida em que limita aquele tipo de investigação às perguntas que os instrumentos de pesquisa permitem; e seria positivista, posto que esse constrangimento autoimposto é indicativo de uma determinação, por parte dos sociólogos, de se submeterem aos mesmos rigores que eles veem nas ciências naturais. (BARRETO, 1998, p. 25-26, grifo do autor)

Bryant relaciona como característica do positivismo "a preocupação com o refinamento das técnicas estatísticas e a instrumentalização da pesquisa" (apud Barreto, p. 26).

Nossa pesquisa acadêmica converge para a constatação de fatos - os dados, que julgamos como o substrato significante que faz toda a diferença. Amplos e prestigiados manuais de pesquisa qualitativa são construídos em torno dessa ideia (PATTON, 2001, p. 4). Como se já existissem antes da escolha teórica ou ideológica do pesquisador, os dados ("qualitativos", "quantitativos" ou de outras classificações menos comuns) são "coletados", analisados, processados. A certeza vem deles. O próprio Comte já dissera: "Tudo que é positivo, isto é, fundado em fatos bem constatados, é certo" (1983, p. 36). Nossa tradição é, basicamente, dataoriented (ALVESSON e SKÖLDBERG, 2004, p. 12-51). Durkheim marca fortemente a posição "adjutória" e "harmonizadora" das "noções e conceitos, os quais, seja qual for o nome que lhes queiramos dar, não são substitutos legítimos para as coisas" (1990 [1895], p. 14). E quando olhamos a estrutura de nossas análises, vemo-nos nas palavras de Durkheim que sentenciou:

Não temos senão um meio de demonstrar que um fenômeno é causa de outro: é comparar os casos em que estão simultaneamente presentes ou ausentes, procurando ver se as variações que apresentam nessas diferentes combinações de circunstâncias testemunham que um depende do outro. (DURKHEIM, 1990 [1895], p. 109, grifo nosso)

De qualquer forma, todos sabem que as obras mestras de Comte, Durkheim e outros definidores do positivismo não foram trabalhos teórico-empíricos, mas massivas peças de argumentação de cunho filosófico. Isso mostra, corroborando as conclusões de Kuhn, que o paradigma não é uma fundação racional, reconhecida racionalmente por muitos, mas um consenso social prático entre grupos de pesquisa, e geralmente tem como referência um feito de pesquisa (uma obra) notório. (KUHN, 1989, p. 353-382. Ver também nota ii, no fim deste texto.)

Charles W. Mills, em seu clássico A Imaginação Sociológica (1982), observa que os estudos empíricos tornaram-se centrais nos Estados Unidos. Citando recomendação do próprio Lazarsfeld, corifeu da sociologia positivista americana, Mills afirma (p. 72) que aí há uma ênfase no estudo de fatos contemporâneos, onde é mais fácil fazer a coleta de dados ao estilo desejado, em detrimento da compreensão da história das instituições e de estudos substantivos. E a isso, que ele classificara como "Tendência III" da sociologia contemporânea, faz crítica: 


\begin{abstract}
"Os estudos da realidade contemporânea podem tornar-se facilmente uma série de fatos desconexos e, com frequência, insignificantes, se relacionados apenas com ambientes de pequena escala. Muitos cursos sobre a sociologia americana ilustram isso. [...] Por outro lado, os sociólogos têm a tendência de se tornarem especialistas na técnica de pesquisa de quase tudo: entre eles, os métodos se transformaram em Metodologia. [...] Essas tendências - de dispersar a atenção e cultivar o método - são dignas companheiras, embora não ocorram necessariamente juntas." (MILLS, 1982, p. 31).
\end{abstract}

Considerando que os clássicos do positivismo não fizeram referência a "métodos quantitativos e qualitativos", o retorno a esses traços comuns ou mais abrangentes pode sugerir uma identidade mais profunda e paradigmática entre muitos pesquisadores na área de administração.

\title{
Um confronto metodológico - leituras de Weber
}

Em certos ambientes de pesquisa, pareceria natural ouvir-se: "como é possível viver sem alguma forma de generalização?". Para se ver além do paradigma metodológico do qual, apesar das promessas, muitas abordagens, como mostrado acima, não conseguem livrar-se, pode ser útil um confronto com outras formas completamente diversas de produzir conhecimento em ciências sociais, que não passam pelo roteiro da generalização. A particularidade do uso desta pode então aparecer. O espaço e os limites da argumentação aqui necessária nos aterão apenas ao caso de Max Weber, por ter sido o primeiro e mais influente rompimento com o paradigma de ciência em vigor. Para onde Weber chama nossa atenção?

Um confronto (hoje clássico) foi posto há um século por Max Weber à então deslumbrante ciência social positiva de Saint-Simon, Spencer, Comte e Durkheim que capitalizava para si todo o prestígio do método das ciências naturais. A "gaiola de ferro" em que se sentia o sociólogo, dado o caráter absorvente e absolutista da forma de racionalidade que seu meio intelectual lhe impunha (MITZMAN, 2002, p. 219), tinha que ser rompida.

Assim como se identificou, na sessão acima, a previsão, predição e controle como sendo o interesse profundo do método empírico das ciências naturais, deve-se procurar também no interesse pelo conhecimento em si, o método de Weber para as "ciências da cultura" (como ele as chamava): compreender o sentido das ações das pessoas, descobrir por que agem de certa maneira. Para Weber, o sentido ou "fim" da ação se torna a sua "causa" explicativa (WEBER, 1979, p. 65), exatamente ao contrário das ciências naturais, onde à explicação só interessa a causa eficiente ("originante"), que gera cadeia de fatos, descrição, controle e previsão de processos, e onde não se discute o "para que" do mundo e dos objetos de estudo.

Weber desenvolveu seu pensamento a partir do que já vinha sendo pensado, sobretudo nos países de língua alemã, como "hermenêutica da história" ou dos produtos culturais históricos (história, não no sentido de cadeia de ocorrências passadas, mas no de presença humana no tempo, qualquer tempo). Wilhelm Dilthey (1833-1911) se preocupou em fundamentar o conceito de compreensão como método dessa hermenêutica. Assim, por oposição à natureza, o interesse se voltava para a história e, por oposição à explicação causal do mundo físico e psicológico, surge a interpretação da cultura humana como compreensão (de um modo geral chamada de Verstehen), "diferente de tudo o que podiam ou quereriam levar a cabo as fórmulas do conhecimento exato da natureza" (WEBER, 1979, p. 50). Essa oposição de campos e métodos de ciência se baseia no consenso de que aquilo que se tem em mente (ou o significado) não é um elemento da natureza, mas da cultura (a "mente objetiva", na expressão de Dilthey), e na

[...] ideia de que este mundo social não pode ser entendido da mesma maneira que o mundo natural, porque os interesses cognitivos que orientam o conhecimento do primeiro são distintos daqueles que orientam o conhecimento do mundo natural. [...] Enquanto as 
ciências sociais se interessam por aquilo que é único ou singular, as ciências naturais se interessam pelo que é geral ou, mais apropriadamente, pelo que se repete. (HAMLIN, 1998, p. 86-87)

Weber dá uma grande contribuição à Verstehen, a ideia de compreensão. Não se trata de alguma "revivência empática de ações alheias" na subjetividade do pesquisador, mas de um trabalho racional, ainda que inclua intuição. Citando o comentário de Gabriel Cohn (2003) sobre isso, diz Paiva (1997, p. 45):

De fato, Weber destaca que "não é preciso ser César para compreender César", isto é, que não é preciso revivenciar César para compreendê-lo. Bastaria procurar os fins almejados por suas ações, assim como os meios que possuía para realizá-los, para tornar sua ação inteligível. [...] De qualquer forma fica evidente o papel que tem a "compreensão": num caso ou noutro, trata-se de um instrumento de apreensão daquilo que, em nossa ciência, é considerado como relevante para estudo.

Posto que as Ciências da Cultura são um discurso histórico sobre agentes reais, singulares e presentes (pela cultura), e não nomológico (visando chegar a leis regulares), Weber insiste no lugar que têm no seu método a teoria e - coisa que ele distingue - a criação de tipos ideais. A teoria tem função instrumental e auxiliar para o conhecimento, e o conceito, função heurística (WEBER, 1992, p. 127). Aí se sente o contraste em relação ao ideal naturalista da generalização. Diz ele:

Ocorre que o estabelecimento de tais regularidades não é a finalidade, mas sim um meio de conhecimento. [...] Para as ciências exatas e da natureza as leis são tanto mais importantes e valiosas quanto mais geral é a sua validade. Para o conhecimento das condições concretas dos fenômenos históricos, as leis mais gerais são, frequentemente, as menos valiosas, por serem as mais vazias de conteúdo. [...] No campo das ciências da cultura, o conhecimento do geral nunca tem valor por si próprio, [...] porque o conhecimento de leis sociais não é um conhecimento do socialmente real, mas unicamente um dos diversos meios auxiliares de que nosso pensamento se serve para esse efeito.” (WEBER, 1992, p. 130)

Não se pode dizer, antecipadamente, a forma como elementos teóricos entram no processo de compreensão do singular, reduzindo-a a procedimento metodológico padrão. No trecho a seguir também aparece a função metodológica de qualificações individuais do pesquisador.

Se o conhecimento causal do historiador consiste na imputação de certos resultados concretos a determinadas causas concretas, então é impossível uma imputação válida de qualquer resultado individual sem a utilização de um conhecimento nomológico, isto é, de um conhecimento das regularidades das conexões causais. [...] Saber até que ponto o historiador (no sentido mais lato da palavra) é capaz de realizar com segurança essa imputação, com o auxílio de sua imaginação metodicamente educada e alimentada pela sua experiência pessoal de vida, e até que ponto estará dependente do auxílio de determinadas ciências especializadas postas ao seu alcance, é algo que depende de cada situação particular." (WEBER, 1992, p. 129-130)

E assim, com Weber, tomamos distância do paradigma científico das ciências exatas e da natureza. Weber discute amplamente o que chama "objetividade" - conceito que associa à qualidade das leis gerais. Em nenhum momento, porém, se detém especificamente em "generalização", mecanismo lógico indutivo, interno às ciências empiristas. Ainda assim, para analisar os casos e fenômenos encontrados no mundo social (a "sociologia real"), o método aperfeiçoado por Weber tem se mostrado de extrema fecundidade. 


\section{A generalização "transfigurada"}

A crítica reiterada ao tipo de pesquisa social empírica expandido entre as décadas de 40 e 60 do século passado nas escolas americanas ou sob sua influência (seção "Tornamo-nos todos positivistas", acima), além do próprio distanciamento natural das suas origens, levou a redefinições da generalização no contexto da pesquisa que se denominou "qualitativa". Seguindo o estudo de Johnson e Duberly (2006, p. 38-61), é nossa posição que essas redefinições se mantêm devedoras da perspectiva positivista original, procurando conceitos que operam efeito similar, e também prestigiado, na pesquisa dissidente do paradigma. Essa seção faz referência a algumas delas. Antes, porém, caracteriza a tradição em que se situam.

\section{O selo "pesquisa qualitativa"}

O emprego generalizado da expressão "pesquisa (ou método) qualitativa" e um não menos consensual e bem sedimentado reconhecimento de sua inadequação (GOODE e HATT, 1973, p. 398; MINAYO, 2000, p. 2831) mostram claramente o débito dos pesquisadores ao paradigma da moderna ciência natural, descrito acima. A identidade dessa "pesquisa alternativa" se define em função da linguagem típica daquele paradigma, a da matemática, orientada para falar da multiplicidade, extensão, ocorrência e relações de fatos, caracterizados de tal forma que possam ser computados. A expressão "pesquisa quantitativa", que não é originária nem das ciências naturais nem do positivismo que as estendeu ao social, surgiu junto com os esforços "dissidentes". O "selo" "qualitativo" refere-se, de fato, a um binômio...

Sharan Merriam diz que:

Pesquisa qualitativa é um conceito guarda-chuva cobrindo diversas formas de investigação que nos ajudam a entender e explicar o sentido dos fenômenos sociais com o mínimo de ruptura dos contextos naturais. Outros termos frequentemente intercambiáveis são 'investigação naturalística', 'pesquisa interpretativa', 'estudo de campo', 'observação participante', 'pesquisa indutiva', 'estudo de caso' e 'etnografia'. Alguns escritores se referem a estes e outros termos como tipos de pesquisa qualitativa. (MERRIAM, 1998, p. 5)

O Handbook of Qualitative Research, obra coletiva coordenada por Norman Denzin e Yvonna Lincoln, segunda edição (2000), representa talvez o melhor trabalho de sistematização dessa tradição de pesquisa relativamente recente nos Estados Unidos e sua área de influência acadêmica. Escrevendo longa introdução à coletânea, em uma retrospectiva sistematizada, os autores descrevem o "campo" como o resultado de um complexo entrecruzamento de tendências e contribuições, "uma trilha entre a pesquisa disciplinada e a expressão artística" - como se esta não exigisse método e disciplina mental do artista - e declaram "partilhar uma crença nas limitações do positivismo e de seu sucessor, o pós-positivismo" (p. xi).

A revisão histórica de Denzin e Lincoln distingue "sete momentos", embora pelas datas de publicações principais de cada "momento" não se deva considerar muito a sequencialidade da classificação. Apesar de, na distinção desses momentos, ficarem claros o viés antropológico dos autores (2000, p. 11-18) e uma discutível tendência a rotular como "pesquisa qualitativa" obras diversas nas humanidades e ciências sociais, assim apresentam os autores sua síntese:

Esses sete momentos se sobrepõem e atuam simultaneamente no presente. Definimo-los como o tradicional (1900-1950); o modernista ou época áurea (1950-1970); o da nãodistinção de gêneros ["blurred genres", seguindo proposta de Geertz de que as ciências sociais e humanas se tornaram indistintas] (1970-1986); a crise de representação ["erosão de normas metodológicas clássicas da antropologia e problematização de questões como 
validade, confiabilidade, objetividade, que antes eram consideradas pacíficas"] (19861990); o pós-moderno, um período de etnografias novas e experimentais (1990-1995); a investigação pós-experimental (1995-2000); e o futuro, que é agora (2000). (DENZIN e LINCOLN, 2000, p. 3)

Ainda segundo os autores, a pesquisa qualitativa tem distintas histórias na educação, no serviço social, nas comunicações, na psicologia, história, estudos organizacionais, ciências médicas, antropologia e sociologia. $\mathrm{Na}$ referência às tendências que se dizem pertencentes ao campo, encontram-se mesmo algumas que confessam epistemologias empiricistas e positivistas (DENZIN e LINCOLN, 2000, p. 24), embora digam os autores que dificilmente, hoje, a pesquisa qualitativa pode mais ser vista sob uma perspectiva de neutralidade e objetividade positivista (p. 18). "Um embaralhamento de escolhas caracteriza agora o campo da pesquisa qualitativa [...e] diversos critérios de avaliação competem por atenção nesse campo” (p. 18).

Se considerarmos bem esta última proposição dos autores, abre-se espaço para dúvidas sobre a consistência da identidade do campo, por eles tentativamente construída. Onde estaria ela? No fato de ser "um espaço de práticas interpretativas múltiplas" (p. 6)? Na "ênfase em qualidades de entidades e em processos e significados que não podem ser examinados experimentalmente e medidos - ou não podem ser medidos de forma alguma - em termos de quantidade, grandezas, intensidade e frequência (p. 8)? Ou seja, no não-uso de instrumental estatístico em suas análises? Na característica de ser "o pesquisador qualitativo um bricoleur e um quilt maker" (p.4)? Mesmo que os autores digam que "a pesquisa qualitativa é, de direito próprio, um campo de pesquisa" (p.2), aqueles traços não só seriam muito pouco para credenciar a pesquisa qualitativa a uma discussão epistemológica, quanto a deixariam, em muitos casos de pesquisa não-antropológica, incluída no que Bryant, acima citado, chamou "positivismo instrumental" da sociologia americana.

Diante disso, parece que as muitas definições de pesquisa qualitativa oferecidas pelos manuais soam como particulares ou formalistas. Fundamentalmente, falta à pesquisa qualitativa marco e raízes epistemológicos históricos, como se deu para o positivismo, como acima descrito; ou então não associamos devidamente esses afastamentos do positivismo às mudanças filosóficas cruciais do Séc. XIX ou primeira metade do Séc. XX que levaram à fenomenologia, às hermenêuticas histórica, social e crítica, ao interacionismo simbólico (G. Mead) e mesmo à Verstehen de Weber. Por outro lado, seria interessante investigar como essas tradições das humanidades e das ciências sociais foram entendidas fora dos EUA. Sem um retorno sério a essas raízes autênticas, qualquer que sejam as implicações dele para o redesenho teórico, a ideia de um selo racionalmente usado, sem dúvida - emerge como aplicável à metodologia qualitativa. Ele tanto pode simbolizar afinidades entre certos grupos de pesquisadores (pelas características acima referidas), quanto trazer legitimidade ao acadêmico praticante que opta por certos procedimentos recolhidos pelos livrosmanuais de metodologia qualitativa e mais correspondentes ao seu feeling de pesquisador desapontado com os métodos quantitativos. É difícil não ver em tudo isso dois traços fortes da cultura norte-americana: o ecletismo ideológico e o pragmatismo, a associação entre os dois representada pela frase: “combinemos os métodos para melhores resultados".

Assim, o termo "pesquisa qualitativa" deveria ser usado e entendido em sua dimensão social - certa tradição de pesquisadores das ciências sociais e humanas, com liderança acadêmica norte-americana - já que é pouco sustentável seu significado metodológico específico. Contudo, essas características praticadas em academias durante as últimas décadas já podem configurar-se como um paradigma de pesquisa, na forma aqui conceituada.

\section{Algumas "redefinições qualitativas" da generalização}

A crítica epistemológica e as situações próprias da tradição de pesquisa qualitativa ocasionaram o desenvolvimento conceitual e metodológico de variações sobre o tema "generalização". Algumas parecem perfeitamente legítimas (epistemologicamente sadias), mas intriga o fato de se apresentarem como formas 
alternativas de generalização, como a não abandonar de todo a referência a esse paradigma de pesquisa empírico-positivista, de alguma forma reconhecendo-o como matriz de validação. Assim, em breve referência às mais significativas, os parágrafos seguintes fazem observações críticas com argumentos que levariam a afirmar, pelo menos para o conjunto delas, tratar-se de redefinições ambíguas e mal contextualizadas da generalização. Ou melhor: complicações desnecessárias.

Primeira redefinição. A comparação entre casos permitindo extensões - na verdade algo essencialmente também próprio a tradições metodológicas quantitativas - já foi sistematicamente tratada há mais de vinte anos (RAGIN, 1987). Mesmo elogiando-o como "poderoso mecanismo conceitual e estratégia epistemológca", Stake (2000, p. 444) diz que a comparação compete com a aprendizagem a partir de um caso particular e que é o oposto daquilo que Clifford Geertz chama "descrição densa". Com a concentração nas bases de comparação, a unicidade e complexidade dos casos serão obscurecidas.

A comparação sistemática de casos pode assumir, contudo, contornos muito formais, quase a fazer uma mímica da generalização clássica, retroagindo, para isso, à montagem do caso:

Discutem-se várias possibilidades de planejar o caminho do caso para a teoria, de forma a permitir que o pesquisador consiga ao menos certa generalização. Na primeira etapa esclarece-se qual o grau de generalização procurado e que pode ser obtido com o estudo concreto, de forma a originar demandas adequadas quanto à generalização. A segunda etapa consiste na integração cautelosa de diferentes casos e contextos, nos quais as relações em estudo são empiricamente analisadas. A capacidade de generalização está, em geral, intimamente relacionada à forma como a amostragem é feita. [...] A terceira etapa é a comparação sistemática do material colhido. (FLICK, 2004, p. 241, grifos nossos)

Após notar que, começando os procedimentos pela definição do grau de generalização desejado, com esta certamente haveriam de terminar, é difícil dizer se essa prática ainda pertence à tradição qualitativa.

Segunda Redefinição. Esforçando-se por justificar o que "apenas parece ser generalização", Yvonna Lincoln e Egon Guba (1985) disseram que a pesquisa qualitativa permite "transferibilidade de contextos", e Crombach (1980) fala de uma "extrapolação razoável”. Realmente, essas estratégias não são generalização - aliás, por que a referência a esta, ao tratar de estratégias qualitativas? Note-se, porém, a vulnerabilidade das justificativas, justamente na analogia que desejam guardar com o movimento da generalização: a) quanto à "transferibilidade de contextos", hoje é assente em Linguística que o significado de um fato é indissociável, semântica e pragmaticamente, de seu contexto (VAN DIJK, 1980); b) quanto à "extrapolação razoável", o conceito matemático preciso de extrapolação se perde na imprecisão do "razoável". Então as justificativas não terminam a discussão, iniciam outra.

Terceira redefinição. $O$ método de comparação constante, sistemática e ascendente, de observações básicas, interpretadas com certa liberdade, na direção da construção de estruturas teóricas mais complexas, a conhecida Grounded Theory, tem atraído mais o interesse de pesquisadores sensíveis ao apelo estruturalista formal. A "descoberta" de Glaser e Strauss (1967), de fato precedida por outros trabalhos, sobretudo do primeiro, originou, anos depois, desdobramentos procedimentais por Corbin e Strauss (1990), que registraram comercialmente o método e criaram um periódico (Grounded Theory Review). A Grounded Theory, surgida na década de 60 do século passado, quando a própria tradição qualitativa não conhecia ainda a crítica epistemológica pós-moderna à generalização, carrega consigo três restrições: a) a fragilidade da lógica indutiva (POPPER, 1989, p. 28, 279-288; CHALMERS, 1999, p. 23-35); b) a concepção artificial da montagem arquitetônica de teorias, que não convence porque, nas humanidades e nas ciências sociais estas não são modelos lógicos, algoritmos de finalidade técnica, mas criações integradas por uma ideia, indivisíveis e aproximativas à realidade social, para interpretá-la livremente, e, c) a ambiguidade da "saturação teórica", que, segundo a Grounded, encerraria a pesquisa: a que se refere, precisamente? À completude de algum desenho representativo, que conduz subjetivamente o pesquisador? A um processo psicológico subliminar (e pouco objetivo) de esgotamento da curiosidade dele? Ou a "saturação" seria 
simplesmente a dificuldade de fontes para prosseguir no movimento analítico-indutivo de dados? Obviamente, a metáfora "saturação" fica à busca de um tópico (referido) apropriado.

Quarta redefinição. A generalização teórica (ou analítica). Robert Yin no seu conhecido "Case study research: design and methods" (1 $1^{\mathrm{a}}$ edição de 1984) menciona, quase de passagem, uma distinção interessante para a época da primeira edição do livro. Referindo-se à "preocupação muito comum" em relação à generalização científica nos estudos de caso, ele diz:

Uma resposta muito breve é que os estudos de caso, da mesma forma que os experimentos, são generalizáveis a proposições teóricas, e não a populações ou universos. Nesse sentido, o estudo de caso, como o experimento, não representa uma "amostragem", e o objetivo do pesquisador é expandir e generalizar teorias (generalização analítica) e não enumerar frequências (generalização estatística). Ou, como descrevem três notáveis cientistas sociais em seu estudo de caso único, o objetivo é fazer uma análise "generalizante" e não "particularizante" (LIPSET, TROW E COLEMAN, 1956, p. 419-420).” (YIN, 2001, p. 29, grifo do autor)

Yin parece não ter amadurecido duas boas intuições, acima apenas embrionariamente referidas. Na primeira, o experimento, como os estudos de caso, de fato remete a outro processo lógico, o dedutivo; nele, porém, não há generalização, ao contrário dos processos indutivos, porque a experimentação já se dá guiada por uma formulação geral, a hipótese, como ponto de partida, e não de chegada (a generalização, a partir dos casos). Na segunda, a referência a "populações ou universos" (objetos do mundo real), por oposição a "proposições teóricas", seria um veio promissor para esclarecer-se o mal-entendido linguístico envolvido no que chama de "generalização teórica" (como Flick e Stake, a seguir comentados) ou "analítica". Entretanto, o autor para aí, invocando como apoio apenas "o objetivo do pesquisador", quando o problema consiste em justificar tal objetivo prático ("expandir e generalizar teorias"). Onde Yin parou, Flick (2004) e Stake (1995) avançaram.

Flick (2004, p. 241) também se refere à "generalização de conceitos e relações encontrados". Idêntica é a ideia de que os estudos qualitativos, sobretudo os de caso, admitem uma generalização precisamente na interpretação que recebem (por ex., ERICKSON, 1986). Stake é absolutamente claro sobre isso. A interpretação é, por si mesma, diz ele (1995, p. 7), uma generalização, e "crescentemente, a generalização é refinada - não uma nova generalização, mas a generalização modificada. Isso é comum na pesquisa".

Ora, há, nos casos acima, um completo mal-entendido e se opera uma substituição semântica. Notando-se, de entrada, que neles foi descartado o significado tradicional de "generalização", justamente o que era problemático para a pesquisa de tradições qualitativas, o mal-entendido consiste em não fazer uma distinção hoje clássica, entre sentido e referência, que vem desde Frege (1892). Na referência, a validade da intenção significante exige uma afirmação denotativa, e só se dá no mundo extralinguístico, onde as coisas correspondem ou não aos precisos termos em que são referidas. No sentido, a validade, independendo disso, se baseia no uso semanticamente correto do signo e da sintaxe, ou seja, é intralinguística (algo pode fazer sentido só pelo modo adequado como é dito, independente de ser ou não "verdade"). Essa distinção, que funda toda a linguística como ciência desde o início do Século XX (SAUSSURE, 1975 [1916]), já está madura e desenvolvida meio século depois, com Benveniste (1966), que fez retificações ao trabalho de Saussure (ARAÚJO, 2004, p. 28-37). Ela implica que a predicação feita em uma análise conceitual, em que alguém "desdobra" corretamente, em proposições, o potencial de atribuição significativa de um conceito, como faz a "generalização conceitual" ou a "interpretação" de que fala Flick, é de ordem diferente daquela em que afirmo objetos ou relações como distintamente existentes no mundo real, por força de "fatos" característicos, anteriormente observados e descritos, como é a intenção da generalização empírica, que implica referência. Além disso, contra uma transposição de sentido feita pelos autores do contexto significado por "generalização" (o da indução empírica de fatos) para o de "generalização conceitual", cabe lembrar que não é estendendo, embora corretamente, pela predicação, a riqueza atributiva de uma teoria, que sua natureza deixa de ser puramente conjectural (POPPER, 1974, p. 1022). 
Para não se arguir, nos casos acima, negligência da distinção entre significação e referência, no patamar proposicional da linguagem, seria preciso dizer que os autores citados abusam da natureza universal ("dessingularizada") inerente a todo conceito (patamar elementar), e grosseiramente confundem generalidade (do conceito) com generalização (da proposição). Como estudou exaustivamente Vygotski (1985), retomando Piaget, os conceitos, após a formação da linguagem na criança, sejam eles quotidianos ou científicos, são de si e sempre gerais ("uni-vers-ais", unum versus alia, algo que se ordena a vários), e a predicação de algo singular só é possível com o uso deles, em uma espécie de movimento inverso, "particularizando" o conceito.

Quinta redefinição. Ao lançar o conceito de "generalização naturalística", Stake (2000) destaca a tradição de autores, Donald Campbell à frente, que centraram seu interesse na dimensão de aprendizagem dos estudos de caso.

\begin{abstract}
A partir dos relatos de casos, tanto o conhecimento propositivo como o experiencial, são desenvolvidos (Geertz, 1983; Polanyi, 1962; Rumelhart e Otony, 1977; Von Wright, 1971). [...] Quando a narração do pesquisador provê oportunidade para a experiência substituta, os leitores estendem suas memórias sobre os acontecimentos. Casos naturalísticos e etnográficos equivalem à experiência, alimentando o processo mais fundamental de consciência e compreensão. Debora Trumbull e eu chamamos esse processo "generalização naturalística" (Stake e Trumbull, 1982). O leitor vem a conhecer algo que lhe é dito, como se ele ou ela o tivesse experimentado. (STAKE, 2000, p. 442, grifo nosso)
\end{abstract}

A ideia da experiência interior substituta tem mais valor objetivo na argumentação sobre a questão aqui tratada, do que mesmo lhe deram os autores que a evocaram (citação acima). Mas isso deve ser dito contra o próprio Stake, não só pela preocupação remanescente com o termo "generalização", mas, sobretudo, quando cita, para esclarecer seu pensamento, David Hamilton que diz: "Em resumo, a generalização naturalística deve ser localizada no reino do conhecimento privado" (STAKE, 1995, p. 86), mostrando, desta forma, que não sai do domínio psicológico nem reconhece valor epistemológico objetivo nas proposições conceituais do pesquisador a partir de seus estudos de caso.

Ora, não se trata de um fenômeno subjetivo e privado, porque os processos sociais e objetivos de linguagem - e este é também o limite significativo de qualquer generalização estatística - só se compreendem e se completam com a introdução do interlocutor em cena, no caso, o leitor (BARROS e FIORIN, 2003). Estudos de caso cumprem muito bem sua finalidade elocucionária sem precisar legitimar-se pelo conceito de generalização (no caso, "naturalística"). E, nesse contexto, cabe acrescentar referência a outra situação, em que se mostra o alcance da dimensão aprendizagem como significado pragmático da comunicação pesquisador-leitor, especialmente nos estudos de caso. Trata-se da força do exemplo, que nesse tipo de textos pode alcançar os diversos níveis de formação e aprofundamento da aprendizagem (FLYVBJERG, 2001, p. 71-73).

Onde chegamos?

\title{
O sentido da ressalva-título
}

Quem quer que, praticando "pesquisa qualitativa", pretenda raciocinar do particular para o geral, dessa forma seguindo o movimento de senso comum ou repetindo acriticamente o paradigma empírico-positivista da 
ciência, acaba caindo em armadilha, e vê-se tentado a repetir a ressalva-título deste ensaio - quando não aderir a re-elaborações engenhosas, mas de fôlego curto, como as descritas nas seções acima. Só estaremos pensando realmente fora do contexto epistemológico que produz a generalização e, portanto, sem nos sentirmos obrigados a ressalvas e conceitos substitutivos, quando não precisarmos usar o vocábulo, simplesmente por ele não caber em contexto de significação alternativo.

O que significa, então, dizer "Os resultados desta pesquisa qualitativa não podem ser generalizados"? - Que o autor, sentindo-se na obrigação de explicar que está fora do paradigma empírico das ciências naturais, com isso envolve-se em um juízo de valor. (De outra forma, sem valoração, estaria dizendo algo como: "eu não posso tirar conclusões na forma do método A, porque estou trabalhando com o método B" - obviedade que não faz sentido supor da parte do autor.) Argumentando pelo oposto: poder-se-ia imaginar o autor de um estudo quantitativo colocando entre as restrições de seu trabalho - pelas quais se sentiria no dever de dar explicações - o fato de que com ele não enriquece intensivamente os conceitos de que trata, nem pode gerar um desencadeador de ação do tipo "efeito-exemplo"? Certamente que não. Então, tem-se, no primeiro caso, pura reverência àquele paradigma, reconhecimento implícito de sua superioridade. O significado da ressalva é valorativo.

\section{Excurso final. Como ficam os protagonistas deste ensaio, a generalização indutiva e a pesquisa qualitativa?}

Resta dizer algo que cabe bem ao contexto deste ensaio, e por isso se apresenta como excurso, em que se tomam duas posições: a primeira, sobre a suposta hegemonia da indução, que tem na generalização, seu mecanismo lógico puro; a segunda, sobre a pesquisa qualitativa, retomando a seção "O selo "pesquisa qualitativa"”, agora em juízo mais amplo.

Primeira posição: sobre a generalização indutiva. Voltemos ao pano de fundo do nosso tema: a lógica da ciência. O século XX trouxe a crise da pretensão totalitária do método da ciência moderna (SANTOS, 2000, p. 55-94; LYOTARD, 1984, p. 25), que passou a ser analisada como apenas um discurso racional e denotativo sobre o mundo, um entre outros e sem unidade entre si (FEYERABEND, 1987), mas cuja legitimação provinha agora, menos de sua formulação veritativa e cada vez mais de sua eficácia técnica e industrial (LYOTARD, 1984, p. 41-47). Enquanto o método de trabalho das ciências naturais pouco mudava no Século XX, eram as ciências humanas e sociais que desenvolviam o seu, inclusive herdando aquele método, através do positivismo. E quando a tentativa de fundamentação final de tal método pelo empirismo lógico "se esfumava sob os golpes de autores como Kuhn, Toulmin, Lakatos e Hesse" (GIDDENS e TURNER, 1999, p. 9), a crise de fundamentação se projetava nelas.

Nesta crise, ou mais especificamente na crise da hegemonia da generalização indutiva, vem a enraizar-se o problema deste ensaio, seu grande contexto, e agora se toma posição a respeito: o método indutivo deixou de ser visto como processo simples ou autônomo e passou a ser entendido dentro de um contexto maior de lógica dedutiva (CHALMERS, 1999, p. 46-63; KUHN, 1989). Com base em Kant, a filosofia moderna havia atribuído consistência própria e base metafísica à indução. Mas esqueceu que, para a racionalidade crítica do grande filósofo da modernidade, a "universalização empírica" (expressão que usa) é presumida e comparativa, não estritamente verdadeira, "uma extensão 'arbitrária' da validade de alguns casos" (FERNANDES, 1985, p. 70-71, grifo do autor, que o extrai do próprio Kant). Ora, Karl Popper, retomando o tema e contestando o positivismo lógico, argumentou pesadamente contra a indução, no que foi amplamente seguido (LAKATOS, 1968; WATKINS, 1984; GILLIES, 1993). Ele afirma simplesmente: "não existe a chamada indução" (POPPER, 2006 [1934, 1972], p. 41), é um mito; ela não é, de fato, praticada, trata-se de uma confusão da lógica com a psicologia do conhecimento. E, para explicar e fundamentar a prática de pesquisa experimental, típica da ciência moderna, propõe o método dedutivo de prova (POPPER, 2006 [1934, 1972], p. 33). Ou seja, o processo lógico sustentável é a dedução - formulações amplas tomadas do campo da ciência ou de fora dele, confrontadas com a experiência sistemática (teste de laboratório ou de 
campo) para rejeição, sustentação ou aperfeiçoamento. Isso fere de morte qualquer pretensão totalitária da generalização empírica. Lembre-se aqui que a argumentação de Popper é recolocada no contexto da crítica ao positivismo lógico da metodologia de pesquisa em administração (JOHNSON e DUBERLEY, 2006, p. 11, 27-33).

Restaria ao processo de acumulação e manipulação estatística de dados uma função heurística, sugestiva de hipóteses (KLIMOVSKY, 1997, p. 128). Cada vez mais em desuso o dogma do positivismo lógico de que só as sentenças experimentais ou diretamente delas deduzidas têm significado real (ROTH, 1987, p. 1-2), acredita-se, há décadas, que a ciência só progride pela inspiração (MEDAWAR, 1969; EINSTEIN, 1981 [1931], p. 140, 148) e por algum tipo de dedução sustentável com argumentos, inclusive os testes empíricos, quando couberem.

Segunda posição: sobre o status metodológico da pesquisa qualitativa. Isso impacta favoravelmente na discussão metodológica da chamada "pesquisa qualitativa". De duas formas: primeiro, porque seu ponto de apoio é justamente a lógica dedutiva, a rede de raciocínios por onde os conceitos se articulam, se apoiam e produzem evidências. Segundo, porque não despreza a experiência - afinal, não se trata de metafísica -, mas esta é tomada em conjuntos (casos, depoimentos, documentos, observações participantes, fatos e circunstâncias históricos, etc.) e contextos densos e indivisíveis, muitas vezes formando um background só. $\mathrm{O}$ esforço da análise se aplica menos à experiência imediata e mais ao conceito que a reconstrói interpretativamente. Não se estaria aí diante de uma forma muito mais rica e autêntica de experiência, integrada ao processo lógico dedutivo? Como não afirmar a superioridade desse método para entender processos humanos e sociais complexos?

O que acabamos de sugerir? Uma inversão de posições na cansada disputa metodológica entre "quantitativistas" e "qualitativistas"? Não. Defenderíamos, como princípio válido, uma composição ótima de métodos quantitativos e qualitativos? Também não, pois nossa dificuldade não é de heurística, é de lógica. Ainda: se boa parte da pesquisa qualitativa traz hoje em seu perfil a sombra da pesquisa quantitativa, quase uma contra-referência em sua identificação, caberia agora - pergunta-se -, invertendo as posições, sugerir "não-qualitativo", como a denominação desejável para métodos de mensuração, testes estatísticos e formas híbridas nas ciências humanas e sociais? De novo, não. A discussão ficaria no plano formal, ao propor-se esse "avesso do avesso". Como a dificuldade já se mostra na falsa assimetria qualitativo-quantitativo (cf. primeiros parágrafos da seção "O selo "pesquisa qualitativa"”), não caberia, logicamente, ao paradigma pesquisa qualitativa "beneficiar-se" diretamente da crise do paradigma moderno das ciências naturais, assumindo imaginada hegemonia.

Por que não pode ir muito longe nosso otimismo com o "qualitativo", enquanto tal? É que o conflito no seio da pesquisa qualitativa existe, como o mostram os próprios esforços, reiterados por décadas, para salvar sua identidade, e este é um caso em que se projeta o dualismo entre ciências naturais e sociais, que permanece mal resolvido (HABERMAS, 1988, p. 1-42, cf. idem, p. xiv):

Não haveria razão para tocar nessa questão bem sepultada do dualismo da ciência se ela não produzisse continuamente em uma área sintomas que demandam uma solução analítica: nas ciências sociais intenções e abordagens heterogêneas entram em conflito e se misturam. (HABERMAS, 1988, p. 2)

Então, das duas uma: ou se reserva o termo "ciência" apenas para a pesquisa ancorada nas "exatas e naturais", ou, a despeito de seu uso na grande mídia e no senso comum, atribui-se a ele um conteúdo mais socioprático do que lógico, aceita a heterogeneidade de que fala Habermas. Herdeira dessa crise histórica de identidade da pesquisa científica, o que se vê é que a denominação "métodos qualitativos" não consegue livrar-se da hibridez conceitual, e ainda não contou com o apoio de um trabalho filosófico que "interprete seu lugar" - para usar a idéia de Habermas (1989, p. 17-35); ou, de outra forma, pode acontecer que perspectiva epistemológica mais ampla, que dê conta dos conflitos e diversidades que o positivismo nos deixou, 
provoque nova aglutinação e sentido para as práticas de pesquisa social hoje. Quem, com Habermas (1990), apostaria na filosofia pragmática da linguagem?

\section{Referências}

ALVESSON, M.; KÄRREMAN, D. Constructing mystery: empirical matters in theory development. Academy of Management Review, v. 32, n. 4, p. 1265-1281, oct/dec, 2007.

ALVESSON, M.; SKÖLDBERG, K. Reflexive methodology: new vistas for qualitative research. London: Sage, 2004.

ARAÚJO, I. L. Do signo ao Discurso: introdução à filosofia da linguagem. São Paulo: Parábola Editorial, 2004.

AUDI, R. (Ed.). The Cambridge dictionary of philosophy. 2. ed. Cambridge: CUP, 1999.

BABBIE, E. R. The practice of social research. 2. ed. California: Wadsworth Publishing, 1979.

BARRETO, T. V. Positivismo, positivismos: da tradição francesa ao positivismo instrumental. Estudos de Sociologia (Recife), v. 4, n. 2, p. 7-31, jul-dez, 1998.

BARROS, D. L. P.; FIORIN, J. L. Dialogismo, Polifonia, Intertextualidade: em torno de Bakhtin. 2. ed. São Paulo: Edusp, 2004.

BENVENISTE, É. Problèmes de linguistique générale. Paris: Galimard, 1966.

CARNAP, R. Studies in inductive logic and probability. L.A.: University of California Press, 1971.

CHALMERS, A. F. O que é ciência, afinal? São Paulo: Brasiliense, 1993.

COHN, G. Crítica e resignação. São Paulo: Martins Fontes, 2003.

COMTE, A. C. São Paulo: Abril Cultural, 1983 [1830-1842] (Coleção Os Pensadores).

CORBIN, J.; STRAUSS, A. Grounded theory research: procedures, canons, and evaluative criteria. Qualitative Sociology, v. 13, n.1, p. 3-21, jan/mar, 1990.

CROMBACH, L. and Associates. Toward reform of program evaluation. San Francisco: Jossey-Bass, 1980.

DAVEL, E; ALCADIPANI, R. Estudos Críticos em Administração: a produção científica brasileira nos anos 1990. In: BERTERO, C. O; CALDAS, M. P; WOOD JR., T. Produção científica em administração no Brasil: o estado da arte. São Paulo: Atlas, 2005.

DENZIN, N. K.; LINCOLN, Y. S. (Eds.). Handbook of qualitative research. 2. ed. London: Sage, 2000. Introduction: the discipline and practice of qualitative research. In: DENZIN, N. K.; LINCOLN, Y. S. (Eds.). Handbook of qualitative research. 2. ed. London: Sage, 2000. p. 1-28.

DIJK, T. A.V. Texto y contexto: semántica y pragmática del discurso. Madrid: Ediciones Cátedra, 1980.

DURKHEIM, É. As regras do método sociológico. 14. ed. São Paulo: Companhia Editora Nacional, 1990 [1895].

DUROZOI, G.; ROUSSEL, A. Dicionário de filosofia. 2. ed. Campinas, SP: Papirus, 1996.

EINSTEIN, A. Como vejo o mundo. Rio de Janeiro: Nova Fronteira, 1981 [1931]. 
ERICKSON, F. Qualitative methods in research on teaching. In: WITTROCK, M. (Ed.). Handbook of research on teaching. New York: McMillan, 1986, p. 119-161.

FERNANDES, S. L. de C. Foundations of Objective Knowledge: the relations of Popper's theory of knowledge to that of Kant. Dordrecht, Holland: D.Reidel Publisshing Company, 1985.

FEYERABEND, P. K. Farwell to reason. London: Verso, 1987.

FLICK, U. Uma introdução à pesquisa qualitativa. Porto Alegre: Bookman, 2004.

FLYVBJERG, B. Making social science matter. Why social enquiry fails and how in can succeed again. Cambridge: CUP, 2001.

FREGE, G. Über Sinn und Bedeutung. Zeitschrift für Philosophie und philosophische Kritik. n. 100, p. 25-50, 1892.

GIDDENS, A.; TURNER, J. Teoria social hoje. São Paulo: UNESP, 1999.

GIERE, R. N. Science without laws. New York: Little Brown and Company, 1999.

GILLIES, D. Philosophy of science in the twentieth century: four central themes. Oxford: Blackwell, 1993.

GLASER, B. G.; STRAUSS, A. L. The discovery of grounded theory: strategies for qualitative research. New York: Aldine, 1967.

GOOD, W.; HATT, P. K. Métodos em pesquisa social. São Paulo: Nacional, 1973.

GRAY, P. S. et al. The research imagination: an introduction to qualitative and quantitative methods. Cambridge: CUP. 2007.

HABERMAS, J. On the logic of the social sciences. Cambridge, Mass.: MIT, 1988.

A Filosofia como guardador de lugar e como intérprete. In: HABERMAS, Jürgen. Consciência moral e agir comunicativo. Rio de Janeiro: Tempo Brasileiro, 1989.

Pensamento pós-metafísico: estudos filosóficos. 2.ed. Rio de Janeiro: Tempo Brasileiro, 1990.

HAMLIN, C. L. A hermenêutica romântica de Willielm Dilthey. Estudos de Sociologia (Recife), v. 4, n. 2, p. 85-99, jul/dez 1998.

HESSEN, J. Teoria do conhecimento. São Paulo: Martins Fontes, 1999.

HUME, D. Investigação acerca do entendimento humano. Livro 1. São Paulo: Companhia Editora Nacional, 1972 $[1748]$.

JOHNSON, P.; DUBERLEY, J. Understanding management research. London: Sage, 2006.

KANT, I. Crítica da razão pura e outros textos filosóficos. São Paulo: Abril, 1974 [1787].

KLIMOVSKY, G. Las desventuras del conocimiento científico. Uma introducción a la epistemología. 3. ed. Buenos Aires: A-Z Editora, 1997.

KUHN, T. A tensão essencial. Lisboa: Edições 70, 1989.

O Caminho desde A Estrutura. São Paulo: UNESP, 2003.

LAKATOS, I. (Ed.) The problems of inductive logic. Amsterdam: North Holand, 1968.

LINCOLN, Y; GUBA, E. Naturalistic inquiry. Beverly Hills, CA: Sage, 1985. 
LYOTARD, J-F. The postmodern condition: a report on knowledge. Minneapolis: University of Minnesota Press, 1984.

MEDAWAR, P. B. Induction and intuition in scientific thought. London: Methuen, 1969.

MENDONÇA NETO, O. R.; RICCIO, E. L.; SAKATA, M. C. G. Dez anos de pesquisa contábil no Brasil: análise dos trabalhos apresentados nos Enanpads de 1996 a 2005. RAE - Revista de Administração de Empresas, v. 49. n. 1. p. 62-73, jan/mar, 2009.

MERRIAM, S. B. Qualitative research and case study applications in education. 2. ed., rev. e ampl., San Francisco: Jossey-Bass, 1998.

MILLS, C. W. A imaginação sociológica. 6. ed. Rio de Janeiro: Zahar, 1982.

MINAYO, M. C. de S. O desafio do conhecimento: pesquisa qualitativa em saúde. 7. ed. São Paulo: Hucitec, 2000.

MITZMAN, A. The Iron Cage: An Historical Interpretation of Max Weber. 2. ed. New Brunswick, N. J: Transaction Publishers, 2002.

MORGAN, G. Paradigmas, metáforas e resolução de quebra-cabeças na teoria das organizações. In: CALDAS, M. P.; BERTERO, C. O. (Orgs.). Teoria das organizações. São Paulo: Atlas, 2007.

NASCIMENTO, A. R.; MARTINS, G. A.; JUNQUEIRA, E. Pesquisa acadêmica em Contabilidade Gerencial no Brasil: análise e reflexões sobre teorias, metodologias e paradigmas. RAC - Revista de Administração Contemporânea, v. 14, p. 1113-1133, nov/dez, 2010.

PAIVA, L. H. Weber e Popper: filosofia das Ciências Sociais. Piracicaba: UNESP, 1997.

PASCAL, G. O pensamento de Kant. 7. ed. Petrópolis, RJ: Vozes, 2001.

PATTON, M. Q. Qualitative research and evaluation methods. 3. ed. London: Sage, 2001.

PFEFFER, J. Mortality, reproducibility and the persistence of styles of theory. Organization Science, v. 6, n. 6, p. 681693, nov/dez, 1995.

POPPER, K. A lógica da pesquisa científica. 12. ed. São Paulo: Cultrix, 2006 [1ª ed., 1934, $3^{\text {a }}$ ed. rev. 1972]. $\overline{2,1974 .}$

Reply to my critics. In: SCHILPP, P. A. (Ed.) The Philosophy of Karl Popper. 2 v. La Salle: Open Court, v.

RAGIN, C. C. The comparative method: moving beyond quantitative and qualitative strategies. Berkeley: UCP, 1987.

RICHARDSON, R. J. (e Colab.). Pesquisa Social - Métodos e técnicas. 3. ed. rev. e ampl. São Paulo: Atlas, 1999.

ROTH, P. A. Meaning and Method in the Social Sciences: a case for methodological pluralism. N.Y: Cornell University Press, 1987.

SAMPAIO, C. H.; PERIN, Marcelo G. Pesquisa científica na área de marketing. RAC - Revista de Administração Contemporânea, v. 10, n. 02, abr/jun, 2006.

SANTOS, B. de S. A crítica da razão indolente: contra o desperdício da experiência. 2 v. São Paulo: Cortez, 2000. v. 1, p. 55-94.

SAUSSURE, F. Curso de Linguística Geral. 7. ed. São Paulo: Cultrix, 1975.

STAKE. R. E. The art of case study research. London: Sage, 1995. 
. Case studies. In: DENZIN, N. K.; LINCOLN, Y. S. (Eds.). Handbook of qualitative research. 2. ed. London: Sage, 2000. p. 435-454.

STAKE, R. E.; TRUMBULL, D. G. Naturalistc generalizations. Review Journal of Philosophy and Social Science, v. 7, n. 7, p. 1-12, 1982 [annual issue].

TONELLI, M. J.; CALDAS, M. P.; LACOMBE, B. M. B.; TINÔCO, T. Produção acadêmica em Recursos Humanos no Brasil: 1991-2000. RAE - Revista de Administração de Empresas, v. 43, n. 1, p. 105-122, jan/mar, 2003.

VERGARA, C. S. Estudos Organizacionais: a produção científica brasileira. In: BERTERO, C. O.; CALDAS, M. P; WOOD JR, T. Produção científica em administração no Brasil: o estado da arte. São Paulo: Atlas, 2005.

VYGOTSKI, L. Pensée et langage: commentaire sur les remarques critiques de Vygotski a Jean Piaget. Paris: Messidor, Ed. Sociales, 1985.

WATKINS, J. Science and skepticism. Princeton: Princeton University Press, 1984.

WEBER, M. Metodologia das ciências sociais. São Paulo: Cortez, 1992.

Sobre a teoria das ciências sociais. 3. ed. Lisboa: Presença, 1979.

WITTGENSTEIN, L. Investigações filosóficas. São Paulo: Nova Cultural, 1996 [1953].

Tractatus Logico-Philosophicus. São Paulo: Cia. Editora Nacional, 1968 [1921].

YIN, R. K. Estudo de caso: planejamento e métodos. 2. ed. Porto Alegre: Bookman, 2001. 